\title{
Teaching and Learning About the Nature of Science
}

\author{
Michael P. Clough ${ }^{1}$
}

Published online: 21 March 2018

(C) Springer Science+Business Media B.V., part of Springer Nature 2018

When Kostas Kampourakis invited me to serve as guest Editor for a special virtual issue of Science \& Education (http://www.springer.com/education+\%26+language/science+education/journal/11191 ?detailsPage=press) in which I would identify what I felt were important articles previously published in the Journal that fit a theme of my choosing, I readily agreed to do so. I have subscribed to SCED since its inception in 1992, and have always valued the Journal's focus on the importance of the history, philosophy and sociology of science for science teaching and learning. After deciding upon Teaching and Learning about the Nature of Science as the theme for the special virtual issue, I began the process of going through each issue of SCED published during its first twenty-five years - from 1992 through 2016 - to read each article title and abstract and determine those that deserved further consideration for inclusion in the special issue. This initial process was both enjoyable and frustrating as I found myself selecting far more articles than I could possibly read in the time I had to finish the special issue. This dilemma reflects the value of articles appearing in Science \& Education regarding the history and nature of science in science education, and it required me to take a more disciplined approach to the task before me. Beginning again with the first issue, I framed my search of articles with the following criteria in mind:

- The connection to teaching and learning about the nature of science (NOS) must be clear;

- Original articles would be given priority over reprints of classic articles; and

- Preference was given to articles that are important and readily intelligible to science teachers and science teacher educators.

Even with these criteria, my initial pass yielded nearly fifty articles for further consideration. Thus, using the same criteria, I more closely examined each of these articles, narrowing to twenty-three that I read in their entirety before selecting the eleven that appear in the special issue. Curious about my final decisions, after having selected the eleven articles, I sought a measure of their impact as reflected in the number of times they have been cited according to Google Scholar. Eight of the eleven articles appearing in the special issue have been cited 118

Michael P. Clough

mclough@tamu.edu

1 Department of Teaching, Learning, \& Culture, Texas A\&M University, College Station, TX 77843-4232, USA 
or more times, and each of the remaining three more than thirty times. So while others tasked with my editor role would unlikely choose the exact same eleven articles, those appearing in the special virtual issue are clearly important for teaching and learning about the NOS.

In the inaugural issue of Science \& Education, the founding Editor, Michael Matthews, addressed the value of the history and philosophy of science for science teaching and learning, and his "History, Philosophy, and Science Teaching: The Present Rapprochement" remains required reading for all who are intent on improving science education. Of course, the social studies of science is an expansive area of scholarship, and what science teachers and science teacher educators should understand about the history, philosophy, and sociology of science and at what depth they ought to understand it in order to improve teaching and learning are complex questions. Many articles in Science \& Education take up these issues, including the following three in the special issue. Douglas Allchin has made many significant contributions to teaching and learning about the NOS, and in "Pseudohistory and Pseudoscience" he shows how quasihistorical accounts distort the NOS, and he then provides warning signs that assist science teachers in spotting such accounts so that they better understand and teach about the NOS. In his "Idealization and Galileo's Pendulum Discoveries", Michael Matthews makes a compelling case that science teachers should understand the role that idealization plays in doing science, not only to understand the NOS, but also to help students develop more robust understanding of much science content. Gürol Irzik and Robert Nola raise concerns about the popular NOS consensus list, and in their "Family Resemblance Approach to the Nature of Science for Science Education" they put forward a comprehensive framework for what teachers must understand about the history, philosophy and sociology of science in order to teach the NOS.

While teachers must accurately understand the history, philosophy, and sociology of science in order to accurately teach the NOS, such understanding - just as with science content understanding - does not ensure effective instruction. Research makes clear that students' attention must be overtly drawn to NOS ideas in a manner that requires them to mentally engage and wrestle with those issues. However, other factors are also important. Anticipating that I would not consider any of my own publications appearing in Science \& Education for this special issue, Kostas kindly told me that I must include my "Learners' Responses to the Demands of Conceptual Change: Considerations for Effective Nature of Science Instruction". Acknowledging the importance of explicit and reflective NOS instruction, this article puts forward that promoting deep and robust learning about the NOS demands that such instruction occur along a decontextualized to highly contextualized continuum with extensive scaffolding back and forth along that continuum. Highly contextualized NOS instruction entails using authentic historical and contemporary science examples that illustrate and provide evidence for claims regarding the NOS, and William McComas in his "Seeking Historical Examples to Illustrate Key Aspects of the Nature of Science" provides a valuable service by identifying historical examples from popular books and linking these to NOS ideas. Sun Kim and Karen Irving report in their "History of Science as an Instructional Context: Student Learning in Genetics and Nature of Science" how overtly addressing NOS issues in lessons infused with history of science improved high school students' understanding of targeted NOS aspects that persisted long after the intervention. In "Teaching With and About Nature of Science, and Science Teacher Knowledge Domains", Fouad Abd-ElKhalick reminds us that merely engaging students in inquiry science experiences will unlikely improve their understanding of the NOS, but that such experiences provide a context whereby knowledgeable science teachers can overtly draw students' attention to relevant NOS ideas. He also argues that teachers possessing deep understanding of the NOS are in a far better position to structure robust inquiry learning environments. 
Preparing teachers who understand the NOS and how to effectively teach it is the focus of Mike Smith's and Lawrence Scharmann's “A Multi-Year Program Developing an Explicit Reflective Pedagogy for Teaching Pre-service Teachers the Nature of Science by Ostention". They propose an instructional approach to teaching preservice teachers about the NOS based on ten well-reasoned postulates that can guide other teacher education efforts that seek to improve NOS teaching and learning. However, beyond understanding NOS content and pedagogy, science teachers must value NOS and learn to overcome institutional constraints that undercut efforts to accurately and effectively teach about the NOS. These issues are taken up by HsingChi Wang and David Marsh in "Science Instruction with a Humanistic Twist: Teachers' Perception and Practice in Using the History of Science in Their Classrooms" and Dietmar Höttecke and Cibelle Silva in "Why Implementing History and Philosophy in School Science Education is a Challenge: An Analysis of Obstacles".

Collectively, the articles in the special virtual issue of Science \& Education reflect how much is known about effectively teaching and learning the NOS. This optimistic take-home message, however, is tempered by the unfortunate acknowledgement that little of what is known is widely implemented in science classrooms. Schools are notoriously conservative institutions, and what Lakin and Wellington wrote in 1994 that NOS instruction appears to be contrary to "expectations held of science and science teaching in schools, not only by teachers and pupils but also those perceived as being held by parents and society" (p. 186) is just as true today. The growth of highstakes examinations which often ignore or inaccurately assess NOS understanding further deters science teachers from devoting meaningful attention to accurately teaching and learning about the NOS. While standards documents often mention the NOS, they too often do so in a perfunctory and superficial manner. And as Höttecke and Silva note in their article appearing in the special virtual issue, standards documents ignore how the history and nature of science matters for teaching and learning science content. All-in-all, recent standards documents do not provide compelling rationales for, or meaningfully promote attention to, teaching and learning the NOS.

Teacher education is equally culpable for the lack of accurate and effective NOS instruction in schools. Too few preservice science teacher education programs require any coursework in the history and nature of science (Backhus and Thompson 2006) and too little time exists in science methods courses to promote a deep and robust understanding of the NOS and NOS pedagogy, and prepare teachers for the fierce institutional constraints they may face in attempting to teach about the history and nature of science. In programs where history and nature of science courses do exist, they too often are designed for graduate students and not required of preservice science teachers. And even in programs where a NOS course is required of graduate students, much further study in the history, philosophy and sociology of science is required of science teacher educators before they are in a sufficient position to promote meaningful attention to the NOS in science education and conduct high quality scholarship.

Quite frankly, most efforts to improve science teacher education and science teaching and learning have not been progressive. If they were, then science standards documents, requirements for science teacher licensure, science teacher education programs, and high stakes science exams would synergistically promote an education in science which would require significant attention to the history and nature of science. Instead, what we have is a potpourri of initiatives, often at odds with one another, that result in a disjointed and confused science teaching landscape that largely promotes training in science - and a poor one at that. Many socio-scientific issues that appear controversial to the general public (e.g., biological evolution, climate change, vaccinations) are largely a result of poor NOS understanding. Science teachers and their students are the casualties of this deplorable situation, and the impact is clearly evident in personal and societal decision-making. 
The way out of this morass will be challenging. Despite the already existing wealth of knowledge regarding teaching and learning about the NOS, much work remains. Future conceptual and empirical work should be directed toward:

- Providing compelling arguments and evidence for what about the NOS is important for students to understand and what level of understanding is desired and reasonable for science literacy and informed personal and socio-scientific decision-making.

- Determining what depth of history and nature of science understanding science teachers must possess in order to accurately and meaningfully engage students in learning about the NOS.

- Establishing minimal science teacher education requirements for preparing teachers to accurately and effectively teach about the NOS.

- How to inculcate among teachers a deep sense of responsibility to accurately and effectively teach about the NOS. Behind successful NOS instruction efforts are teachers who take seriously the importance of NOS learning and their obligation to faithfully represent science to students.

- Preparing teachers to overcome institutional constraints and accurately teach the NOS.

- Investigating how education policy issues, standards documents, high-stakes exams, longstanding school cultures and other factors impact teaching and learning about the NOS. Such efforts are necessary for understanding why science teachers generally place little emphasis on accurately teaching about the NOS.

- The development of more valid and reliable NOS assessments, both for research purposes and for inclusion in science classes and high-stakes exams.

- Providing compelling evidence supporting the contention that NOS understanding promotes science content understanding. While some evidence exists for this claim, the connection must be more convincing to science teachers, school administrators, and policymakers.

- Providing evidence that clarifies the role NOS understanding plays in personal and socioscientific decision-making. Many factors play a role in decision-making, thus the impact of NOS understanding can easily and wrongly be dismissed.

- The role of NOS understanding in combating both scientism and anti-science attitudes.

- How NOS teaching and learning aligns with and supports other research-based science teaching practices.

- Long-term impacts of NOS teaching and learning.

While the above issues do not exhaust all that must be accomplished, what is already known and what will be learned regarding teaching and learning about the NOS will mean little unless NOS scholars become active in science education and science teacher education policy decisions to promote its implementation in schools and informal science education settings. The Teaching and Learning about the Nature of Science special virtual issue illustrates the value of work appearing in Science \& Education, and it seeks to illuminate a way forward that informs research and practice so that in the not-too-distant future, such a special issue will make clear the significant positive impact teaching and learning about the nature of science has had on improving scientific literacy and personal and societal decision-making. 
Toward this end, the editors of Science \& Education invite submissions regarding teaching and learning about the nature of science, especially empirical work related to classroom NOS instruction and teachers' professional development. Such scholarship is of constant interest to Science \& Education, and the editors are eager to publish a special issue with articles reporting recent work on this topic.

\section{Compliance with ethical standards}

Conflict of interest The author declares no conflict of interest.

\section{References}

Lakin, S., \& Wellington, J. (1994). Who will teach the nature of science?: Teachers' views of science and their implications for science education. International Journal of Science Education, 16(2), 175-190.

Backhus, D. A., \& Thompson, K. W. (2006). Addressing the nature of science in preservice science teacher preparation programs: Science educator perceptions. Journal of Science Teacher Education, 17, 65-81. 